\section{Subroutine for generating all permutations of $\mathrm{N}$ integers}

\section{RICHARD PECTER \\ Dartmouth College, Hanover, New Hampshire 03755}

A permutation algorithm proves useful in many social science problems. It is not unusual to want to look at all possible orderings and determine which is "best" according to your own criteria. Since the advent of the computer, this has been relatively feasible. One problem with these programs has been to find one when you need it. Another problem is computer run time, since no matter what method is used to generate permutations, run time increases factorially with length of permutation. This abstract attempts to aid in solving these two problems.

Language. The program is short (22 lines code, 50 lines with comments). It is written in BASIC but can be readily translated to FORTRAN.

Output. Runs through all $\mathrm{N}$ ! Permutations of $\mathrm{N}$ integers in $2 \mathrm{sec}$ for $N=7,15 \mathrm{sec}$ for $N=8$, and $140 \mathrm{sec}$ for $\mathrm{N}=9$ on Dartmouth Time Sharing System. These are all a full order of magnitude faster than the next fastest program I have seen (see Table 1).

Availability. Requests for copies of the program should be sent to Richard Pechter, Dartmouth College, Hinman Box 358, Hanover, New Hampshire 03755.

Table 1

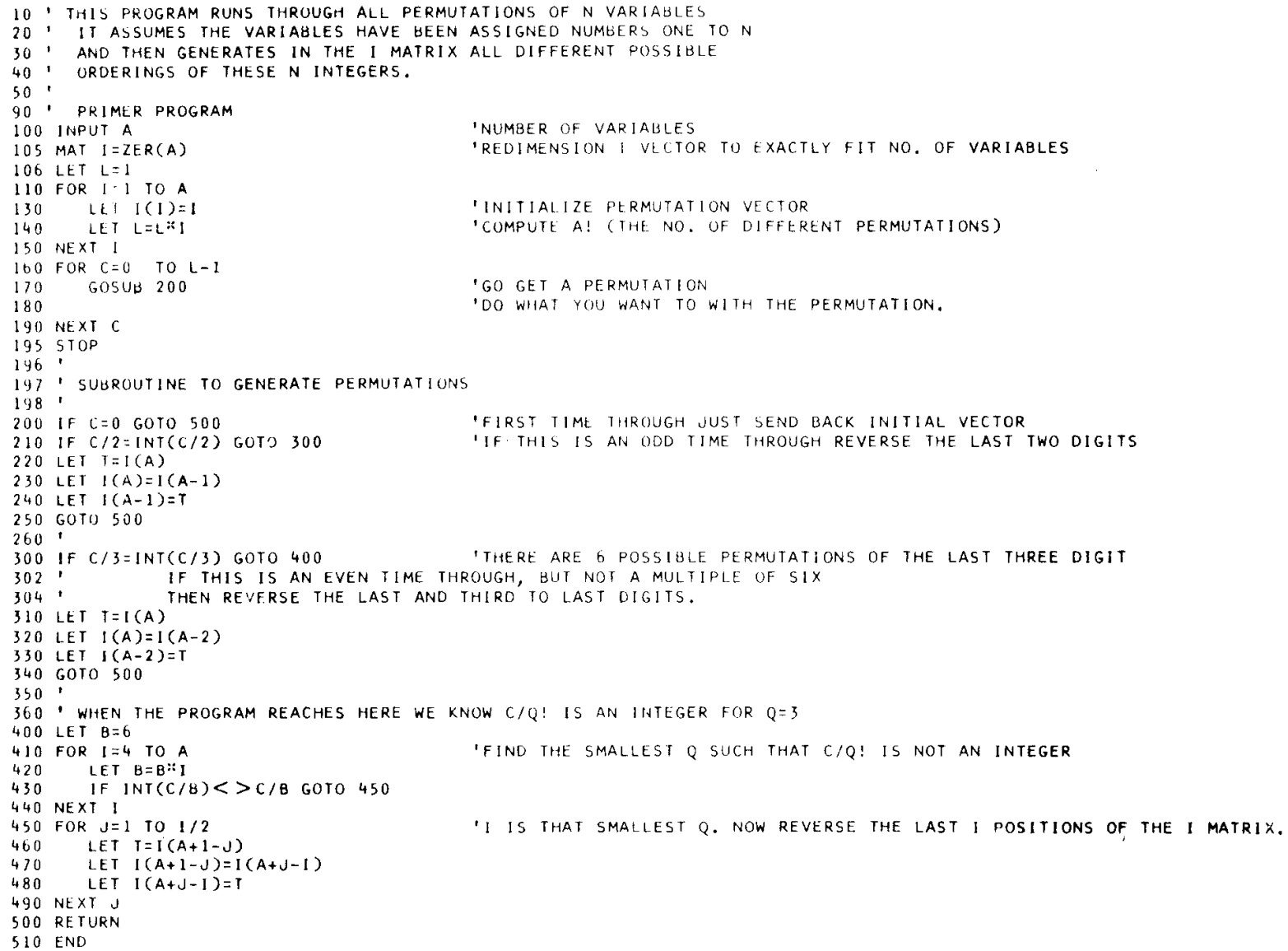

